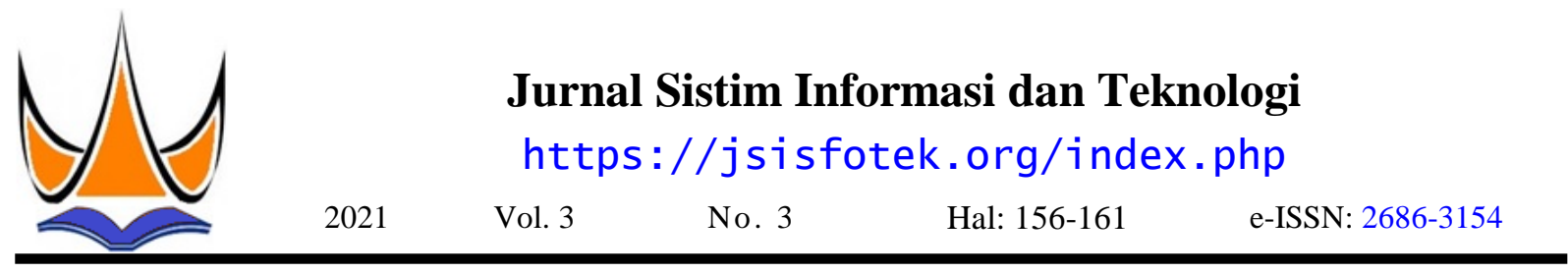

\title{
Kompetensi yang Optimal Terhadap Penilaian Kinerja Guru dengan Metode Simple Additive Weighting
}

\author{
Alfarisdon $^{1 凶}$,Sumijan $^{2}$, Gunadi Widi Nurcahyo ${ }^{3}$ \\ ${ }^{1}$ SMP Negeri 25 Padang \\ ${ }^{2,3}$ Universitas Putra Indonesia YPTK Padang \\ a]farisdon@gmai1.com
}

\begin{abstract}
Professional teachers should be able to improve their quality to achieve the vision and mission of the school where the teacher is carrying out their duty. The main task of an educator is to provide students with the process of learning, educating, training and giving directions to create a better learning process. Besides carrying out the task of teaching, an educator also needs to be able to develop themselves sustainably in order to increase self-competencies. There are four competencies should be owned by an educator they are pedagogic, personality, social and professional. To measure those competencies, school head master have to conduct teacher assessment by pointed assessors. Teacher performance assessment functions to analyses teachers ' professionalism in learning processes at a school, teachers participation on self-empowerment activities as well as capacity building. This study aims to calculate the value of teacher performance assessment optimally based on competence through a decision support system. Simple Additive Weighting method is used in this decision support system. By using Simple additive weighting, the sum of weight ratings performance on each alternative in all the attributes can be collected. This decision support system used to make it easier to take a decision and a supporter of decision in performance evaluations. Dataset treat in this research was collected in SMP Negeri 25 Padang. The data consisting of four different criteria in accordance with teacher competence. The result of the study reaches the level of accuracy of $100 \%$. This study is expected to bring benefits for school leaders as the reference in order to optimize the teacher performance evaluation objectively.
\end{abstract}

Keywords: Teacher, Teacher Performance Assessment, Teacher Competencies, Decision Support System, Additive Weighting Method.

\begin{abstract}
Abstrak
Guru professional harus mampu meningkatkan kualitasnya demi tercapainya visi dan misi pendidikan disekolah tempat dimana guru tersebut melaksanakan tugasnya. Tugas utama seorang pendidik adalah untuk memberikan pembelajaran, pendidikan, memberikan latihan dan memberikan arahan kepada siswa agar memiliki kesiapan dalam proses menerima pembelajaran dengan baik. Selain melaksanakan tugas mengajar guru juga harus mampu mengembangkan diri secara berkelanjutan untuk dapat meningkatkan potensi diri. Empat Kompetensi yang harus dimiliki oleh seorang pendidik adalah pedagogik, kepribadian social dan profesional. Untuk mengukur kompetensi tersebut, perlu dilakukan Penilaian Kinerja Guru oleh kepala sekolah melalui asesor yang sudah di tugaskan. Penilaian Kinerja Guru merupakan proses yang digunakan untuk menganalisa agar guru bias menjadi pendidik profesional yang mampu member pengajaran, pendidikan lebih baik kepada siswa dan aktif dalam berbagai kegiatan pengembangan diri untuk meningkatkan kompetensinya. Penelitian ini bertujuan untuk menghitung Penilaian Kinerja Guru Mata Pelajaran yang optimal sesuai kompetensi yang harus dimiliki melalui Sistem Pendukung Keputusan. Sistem Pendukung Keputusan mengunakan Metode Simple Additive Weighting. Pada Metode Simple Additive Weighting kita dapat mencari penjumlahan bobot dari rating kinerja pada setiap alternatif di semua atribut. Sistem Pendukung Keputusan ini digunakan untuk mempermudah mengambil keputusan maupun pendukung keputusan dalam Penilaian Kinerja Guru Mata Pelajaran. Data set yang diolah dalam penelitian ini bersumber dari SMP Negeri 25 Padang. Data set terdiri dari empat criteria berbeda, sesuai dengan kompetensi yang harus dimiliki guru. Penelitian ini memiliki hasil dengan tingkat akurasi $100 \%$. Hasil penelitian ini diharapkan dapat bermanfaat bagi unsure pimpinan sekolah sebagai acuan untuk mengoptimalkan penilaian kinerja guru secara objektif.
\end{abstract}

Kata kunci: Guru, Penilaian Kinerja Guru, Kompetensi Guru, Sistem Pendukung Keputusan, Simple Additive Weighting.

(C) 2021 JSisfotek

\section{Pendahuluan}

terwujudnya visi dan misi pendidikan disekolah tempat

Pendidik adalah seorang guru yang memiliki tugas dimana guru tersebut melaksanakan tugasnya.

utama untuk memberi pembelajaran, mendidik, Pendidik profesional adalah guru yang mengedepankan membina, serta mengarahkan peserta didik agar kemampuan dan kualitas diri dalam berbagai bidang memiliki kesiapan dalam menghadapi persaingan diera sesuai kompetensi yang harus dimilikinya. Kemampuan kemajuan teknologi. Oleh karena itu posisi guru guru harus memenuhi standar kebutuhan didalam sebagai tenaga profesional sangatlah penting dalam masyarakat, pendidikan nasional, serta memaksimalkan kemampuan siswa berdasar potensi dan kecakapan

Diterima: 30-03-2021 | Revisi: 16-04-2021 | Diterbitkan: 30-09-2021 | DOI: 10.37034/jsisfotek.v3i3.57 
yang dimiliki masing-masing peserta didik. Agar dapat dalam memilih guru berprestasi secara valid untuk menjadi guru yang profesional seorang guru harus waktu yang akan datang [10].

mampu memiliki beberapa kompetensi [1]. Kompetensi yang harus dimiliki guru adalah kompetensi pedagogik, kompetensi kepribadian, kompetensi sosial dan kompetensi profesional.

Untuk mencapai kompetensi tersebut guru perlu meningkatkan potensinya baik dibidang pengajaran maupun pengembangan diri yang berkelanjutan. Agar potensi guru tersebut dapat diukur menjadi sebuah standar maka perlu dilakukan Penilaian Kinerja Guru. Penilaian Kinerja Guru merupakan proses untuk Sistem Pendukung Keputusan merupakan sistem yang menganalisis kompetensi guru agar menghasilkan dapat mengolah data dalam mengambil keputusan. pengajaran yang lebih baik [2].

Dalam proses pengambilan keputusan manusia sering dihadapkan pada berbagai alternatif pilihan keputusan, sehingga untuk suatu permasalahan akan terdapat banyak keputusan berbeda yang di ambil oleh pembuat keputusan [3]. Untuk membuat keputusan semi terstruktur, maka Sistem Pendukung Keputusan juga bisa dikatakan sebagai sistem komputer yang mengolah data menjadi informasi [4]. Pada Sistem Pendukung Keputusan pendekatan yang digunakan dalam memeringkat kriteria ini didasarkan pada analisis statistik atau pengalaman para ahli. Ini terutama didasarkan pada analisis preferensi para ahli dalam kaitannya dengan alternatif yang perlu diberi peringkat [5].

Sistem pendukung keputusan memiliki beberapa metode, salah satunya metode Simple Additive Weighting (SAW). Konsep dasarnya dari metode SAW adalah untuk menemukan jumlah tertimbang kinerja peringkat pada setiap alternatif dan pada semua atribut yang membutuhkan proses normalisasi matriks keputusan (Z) ke skala yang sebanding dengan semua peringkat alternatif yang ada [6].

Penelitian-penelitian sebelumnya pernah menggunakan aturan menyelesaikan masalah yang ada, Menentukan metode Simple Additive Weighting (SAW) dalam bobot preferensi atau tingkat kepentingan (W) setiap berbagai bidang permasalahan. Penerapan SAW kriteria, Membuat matrik keputusan (Z) dari rating berhasil digunakan dalam penilaian kualitas guru kesamaan pada setiap alternatif (Ai) dengan setiap mengajar sehingga dapat meningkatkan mutu kriteria $(\mathrm{Cj})$, Melakukan langkah normalisasi matriks pendidikan [7]. Penelitian lain untuk penilaian kinerja keputusan (Z) dengan cara menghitung nilai rating guru kelas dinyatakan mampu mengatasi permasalahan kinerja ternormalisasi (rij) dari alternatif (Ai) pada dalam melakukan penilaian kinerja guru kelas yang kriteria $(\mathrm{Cj})$ dengan rumus yang disajikan pada lebih objektif tanpa ada ketimpangan sosial antara Persamaan 1. pendidik [8].

Simple Additive Weighting (SAW) dalam penelitian $r i j=\frac{x i}{\max x i j}$

Penilaian Kinerja Karyawan dilakukan untuk Hasil dari normalisasi (rij) membentuk matrik menentukan kenaikan jabatan dalam perusahaan, ternormalisasi (U) yang disajikan pada Persamaan 2. memberi bonus gaji pada karyawan yang berprestasi, dengan mengevaluasi hasil kinerja karyawan perusahaan dapat mempermudah Manager untuk menilai karyawan dengan kinerja yang baik dengan lebih adil, valid dan relevan [9]. Penelitian berikut Pada proses selanjutnya dilakukan perhitungan hasil menggunakan SAW untuk menentukan guru berprestasi dengan menentukan skor nilai bobot V. Persamaan menghasilkan keputusan yang yang diharapkan secara untuk mencari hasil akhir bobot $\mathrm{V}$ terdapat pada cepat, akurat dan adil dan dapat menjadi penilaian baru Persamaan 3. 


$$
V=U W
$$

Dimana $\mathrm{U}$ adalah hasil normalisasi matriks $\mathrm{Z}, \mathrm{W}$ merupakan nilai bobot yang telah ditentukan, untuk mencari bobot $\mathrm{V}$ adalah dengan melakukan perkalian $\mathrm{U}$ dengan baris kali kolom, selanjutnya melakukan Perankingan dari rating tertinggi ke terendah.

Pada metodologi penelitian penelitian yang dilakukan dalam rangka penyelesaian masalah yang diteliti, menganalisa permasalahan dari data-data yang diperoleh, memproses data tersebut menjadi informasi yang sesuai dengan penelitian, agar hasil tidak melenceng dari tujuan sebenarnya yang dijabarkan melalui kerangka kerja penelitian. Berikut kerangka kerja penelitian pada Gambar 1.

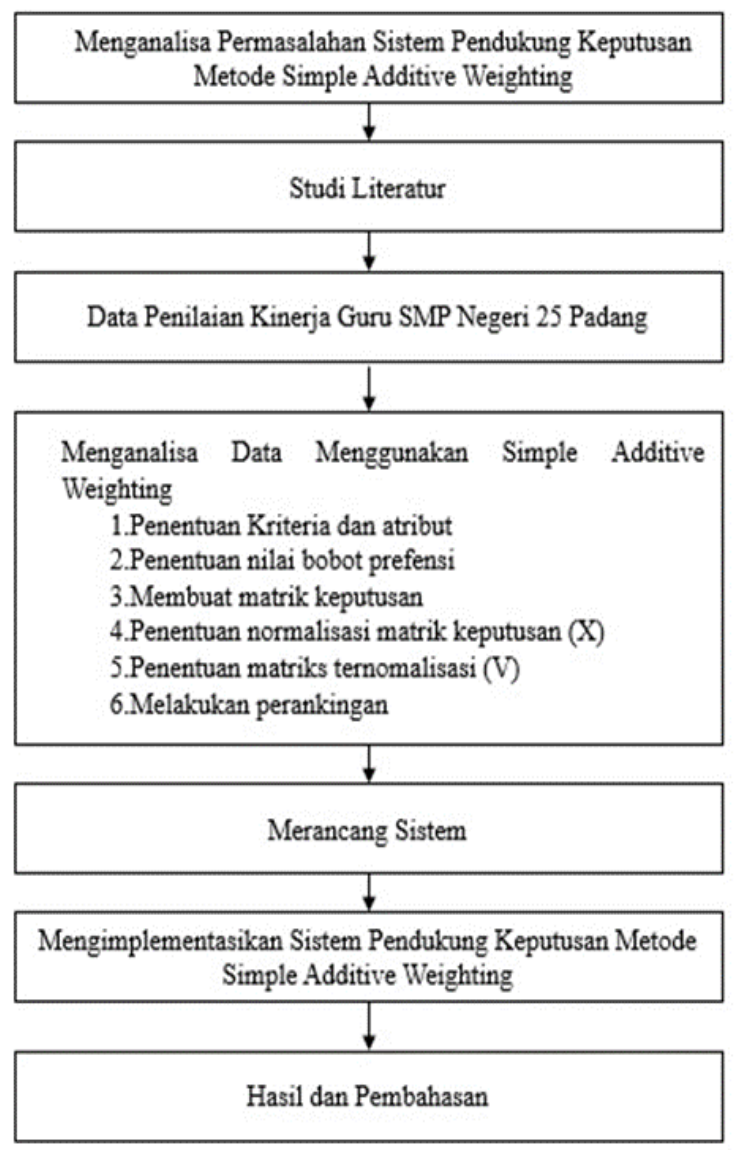

Gambar 1. Kerangka Kerja Penelitian

\section{Hasil dan Pembahasan}

\subsection{Menentukan Alternatif}

Tabel 1. Sampel atau Alternatif

\begin{tabular}{ll}
\hline KodeAlternatif & Nama \\
\hline OL1 & Nelly Fitri \\
OL2 & Afrida \\
OL3 & Apriani Hastuti \\
OL4 & Desfitri \\
OL5 & Emi Susanti \\
OL6 & Eva Ampriati \\
OL7 & Feri Yufrizal \\
OL8 & Fetra Yenti \\
OL9 & Gusmawati \\
OL10 & Irdaviani \\
OL11 & Irdawati \\
OL12 & Ismaizar \\
OL13 & Ismartina Elda \\
OL14 & Laili \\
OL15 & Maswenti M \\
\hline
\end{tabular}

\subsection{Menentukan Kriteria dan Atribut}

Pada penelitian ini, masalah yang ada akan dipecahkan dengan tujuan menentukan Penilaian Kinerja Guru mata pelajaran. Dengan menggunakan sistem ini, akan ditentukan guru yang memiliki kinerja sangat direkomendasi berdasarkan kriteria yang telah ditentukan sebelumnya. Kriteria yang sudah ditentukan adalah kriteria Pedagogik, kriteria Kepribadian, kriteria Sosial, kriteria Profesional. Pada kriteria yang ada diberi bobot kepentingan pada setiap kriteria, dapat dilihat pada Tabel 2 .

Tabel 2. Kriteria

\begin{tabular}{ll}
\hline Kriteria & Keterangan \\
\hline OF1 & Pedagogik \\
OF2 & Kepribadian \\
OF3 & Sosial \\
OF4 & Profesional \\
\hline
\end{tabular}

Sesuai dengan kriteria yang telah ada dapat diberikan bobot kepentingan pada setiap kriteria, dilihat pada Tabel 3.

Tabel 3. Nilai Bobot Kriteria

\begin{tabular}{ll}
\hline Bobot & Nilai \\
\hline OF1 & $25 \%$ \\
OF2 & $25 \%$ \\
OF3 & $25 \%$ \\
OF4 & $25 \%$ \\
\hline
\end{tabular}

Langkah selanjutnya setelah menentukan bobot kriteria Pada Penelitian ini menggunakan 15 buah data guru adalah menentukan matriks prioritas pada subkriteria yang menjadi sampel. Data 15 guru tersebut diolah Penilaian Kinerja Guru (PKG) mata pelajaran sesuai dengan data yang didapat dilapangan berdasarkan kriteria penilaian yang telah ditentukan, berdasarkan kriteria-kriteria yang sudah ditetapkan. dilihat pada OF 1 Tabel 4.

Data tersebut terdapat pada Tabel 1.

Tabel 4. Sub Kriteria OF 1

\begin{tabular}{|c|c|}
\hline Bobot & Keterangan \\
\hline 1 & $\begin{array}{l}\text { Tidak } \\
\text { direkomendasikan }\end{array}$ \\
\hline 2 & $\begin{array}{l}\text { Cukup } \\
\text { direkomendasikan }\end{array}$ \\
\hline 3 & Direkomendasikan \\
\hline
\end{tabular}

Jurnal Sistim Informasi dan Teknologi Vol. 3 No. 3 (2021) 156-161 
Sub kriteria sesuai dengan kriteria PKG mata pelajaran dapat dilihat pada OF 2 Tabel 5.

Tabel 5. Sub Kriteria OF 2

\begin{tabular}{ll}
\hline Bobot & Keterangan \\
\hline 1 & Tidak \\
& direkomendasikan \\
2 & Cukup \\
3 & direkomendasikan \\
4 & $\begin{array}{l}\text { Direkomendasikan } \\
\text { Sangat } \\
\text { direkomendasikan }\end{array}$ \\
\hline
\end{tabular}

Subkriteria berdasarkan kriteria PKG dapat dilihat pada OF 3 Tabel 6.

Tabel 6. Sub Kriteria OF 3

\begin{tabular}{|c|c|}
\hline Bobot & Keterangan \\
\hline 1 & $\begin{array}{l}\text { Tidak } \\
\text { direkomendasikan }\end{array}$ \\
\hline 2 & $\begin{array}{l}\text { Cukup } \\
\text { direkomendasikan }\end{array}$ \\
\hline 3 & Direkomendasikan \\
\hline 4 & $\begin{array}{l}\text { Sangat } \\
\text { direkomendasikan }\end{array}$ \\
\hline
\end{tabular}

Sub kriteria berdasarkan kriteria PKG dapat dilihat pada OF 4 Tabel 7.

Tabel 7. Sub Kriteria OF 4

\begin{tabular}{ll}
\hline Bobot & Keterangan \\
\hline 1 & $\begin{array}{l}\text { Tidak } \\
\text { direkomendasikan }\end{array}$ \\
2 & Cukup \\
& direkomendasikan \\
3 & Direkomendasikan \\
4 & Sangat \\
& direkomendasikan \\
\hline
\end{tabular}

\subsection{Membuat Matriks Keputusan}

Pada tahapan berikutnya adalah melakukan pengolahan data setalah memberikan bobot pada setiap kriteria dan sub kriteria menggunakan Sistem Pendukung keputusan dengan metode SAW terhadap data-data guru yang seperti dapat dilihat pada Tabel 8 .

Tabel 8. Pengolahan Data

\begin{tabular}{llllll}
\hline No & KodeAlternatif & OF1 & OF2 & OF3 & OF4 \\
\hline 1 & OL1 & 4 & 3 & 2 & 3 \\
2 & OL2 & 4 & 4 & 3 & 3 \\
3 & OL3 & 3 & 3 & 4 & 3 \\
4 & OL4 & 3 & 4 & 2 & 4 \\
5 & OL5 & 4 & 4 & 4 & 3 \\
6 & OL6 & 4 & 3 & 3 & 4 \\
7 & OL7 & 2 & 3 & 4 & 2 \\
8 & OL8 & 3 & 4 & 4 & 2 \\
9 & OL9 & 4 & 2 & 2 & 3 \\
10 & OL10 & 3 & 4 & 4 & 3 \\
11 & OL11 & 3 & 3 & 3 & 3 \\
12 & OL12 & 3 & 4 & 2 & 3 \\
13 & OL13 & 2 & 3 & 4 & 3 \\
14 & OL14 & 2 & 4 & 4 & 2 \\
15 & OL15 & 2 & 4 & 4 & 4 \\
\hline
\end{tabular}

Pada proses selanjutnya dilakukan pembuatan matrik keputusan dapat dilihat dari:

$$
\left[\begin{array}{llll}
4 & 3 & 2 & 3 \\
4 & 4 & 3 & 3 \\
3 & 3 & 4 & 3 \\
3 & 4 & 2 & 4 \\
4 & 4 & 4 & 3 \\
4 & 3 & 3 & 4 \\
2 & 3 & 4 & 2 \\
3 & 4 & 4 & 2 \\
4 & 2 & 2 & 3 \\
3 & 4 & 4 & 3 \\
3 & 3 & 3 & 3 \\
3 & 4 & 2 & 3 \\
2 & 3 & 4 & 3 \\
2 & 4 & 4 & 2 \\
2 & 4 & 4 & 4
\end{array}\right]
$$

3.4 Penentuan Normalisasi Matrik Keputusan (U)

Pada proses selanjutnya dilakukan normalisasi terhapat matrik $\mathrm{Z}$ berdasarkan persamaan dari metode SAW dengan hasil:

$$
U=\left[\begin{array}{cccc}
1 & 0,75 & 0,50 & 0,75 \\
1 & 1 & 0,75 & 0,75 \\
0,75 & 0,75 & 1 & 0,75 \\
0,75 & 1 & 0,50 & 1 \\
1 & 1 & 1 & 0,75 \\
1 & 0,75 & 0,75 & 1 \\
0,5 & 0,75 & 1 & 0,5 \\
0,75 & 1 & 1 & 0,5 \\
1 & 0,5 & 0,5 & 0,75 \\
0,75 & 1 & 1 & 0,75 \\
0,75 & 0,75 & 0,75 & 0,75 \\
0,75 & 1 & 0,5 & 0,75 \\
0,5 & 0,75 & 1 & 0,75 \\
0,5 & 1 & 1 & 0,5 \\
0,5 & 1 & 1 & 1
\end{array}\right]
$$

3.5Penentuan Matrik Ternormalisasi (V)

Selanjutnya adalah proses perhitungan dari hasil dengan mencari skor nilai bobot $\mathrm{V}$, Mencari Bobot $\mathrm{V}$ dilakukan dengan mencari perkalian antara $\mathrm{U}$ dengan W baris dikali kolom dengan hasil yaitu:

$\mathrm{V} 1=(1)(0,25)+(0,75)(0,25)+(0,50)(0,25)+$ $(0,75)(0,25)=0,75$

$\mathrm{V} 2=(1)(0,25)+(1)(0,25)+(0,75)(0,25)+(0,75)(0,25)$ $=0,87$

$\mathrm{V} 3=(0,75)(0,25)+(0,75)(0,25)+(1)(0,25)+$ $(0,75)(0,25)=0,81$ 
$\begin{array}{ll}\mathrm{V} 4=(0,75)(0,25)+(1)(0,25)+(0,50)(0,25)+(1)(0,25) & \text { membantu dalam pengambilan keputusan terhadap } \\ =0,81 & \text { penilaian Kinerja Guru dengan lebih objektif dan } \\ \text { efisien, serta dapat diterapkan dengan efektif dalam } & \\ \mathrm{V} 5=(1)(0,25)+(1)(0,25)+(1)(0,25)+(0,75)(0,25)= & \text { memberikan usulan alternative terbaik sesuai dengan } \\ 0,93 & \text { kriteria yang sudah ditetapkan. }\end{array}$

$\mathrm{V} 6=(1)(0,25)+(0,75)(0,25)+(0,75)(0,25)+(1)(0,25)$ $=0,87$

$\mathrm{V} 7=(0,5)(0,25)+(0,75)(0,25)+(1)(0,25)+$ $(0,50)(0,25)=0,68$

$\mathrm{V} 8=(0,75)(0,25)+(1)(0,25)+(1)(0,25)+(0,50)(0,25)$ $=0,81$

\section{DaftarRujukan}

$\mathrm{V} 9=(1)(0,25)+(0,5)(0,25)+(0,50)(0,25)+$ $(0,75)(0,25)=0,68$

$\mathrm{V} 10=(0,75)(0,25)+(1)(0,25)+(1)(0,25)+$ $(0,75)(0,25)=0,87$

$\mathrm{V} 11=(0,75)(0,25)+(0,75)(0,25)+(0,75)(0,25)+$ $(0,75)(0,25)=0,75$

$\mathrm{V} 12=(0,75)(0,25)+(1)(0,25)+(0,50)(0,25)+$ $(0,75)(0,25)=0,75$

$\mathrm{V} 13=(0,5)(0,25)+(0,75)(0,25)+(1)(0,25)+$ $(0,75)(0,25)=0,75$

$\mathrm{V} 14=(0,5)(0,25)+(1)(0,25)+(1)(0,25)+(0,5)(0,25)$ $=0,75$

$\mathrm{V} 15=(0,5)(0,25)+(1)(0,25)+(1)(0,25)+(1)(0,25)=$ 0,87

Dari perhitungan SAW yang telah dilakukan menghasilkan perangkingan seperti pada Tabel 9.

Tabel 9. Perangkingan

\begin{tabular}{lll}
\hline Kode & Nilai & Rangking \\
\hline Olternatif & & Rangking 4 \\
OL2 & 0,75 & Rangking 2 \\
OL3 & 0,87 & Rangking 3 \\
OL4 & 0,81 & Rangking 3 \\
OL5 & 0,81 & Rangking 1 \\
OL6 & 0,93 & Rangking 2 \\
OL7 & 0,87 & Rangking 5 \\
OL8 & 0,68 & Rangking 3 \\
OL9 & 0,81 & Rangking 5 \\
OL10 & 0,68 & Rangking 2 \\
OL11 & 0,87 & Rangking 4 \\
OL12 & 0,75 & Rangking 4 \\
OL13 & 0,75 & Rangking 4 \\
OL14 & 0,75 & Rangking 4 \\
OL15 & 0,75 & Rangking 2 \\
\hline
\end{tabular}

Dari hasil penggunaan metode Simple Addictive Weighting maka dapat ditentukan nilai kompetensi yang paling optimal berdasarkan kriteria keputusan. Hasil proses perhitungan menggunakan metode SAW dapat di lihat alternatife dengan nilai yang tertinggi atas nama Emi Susanti dengan kode alternatif OL 5 dengan nilai akhir 0,93 .

\section{Kesimpulan}

Hasil Akhir dari penelitian yang telah dilakukan menggunakan metode Simple Addictive Weighting
Metode yang berbeda biasa aja menghasilkan kesimpulan yang berbeda, oleh sebab itu penelitian selanjutnya bisa menggunakan Sistem Pendukung keputusan lainnya seperti MOORA, Topsis dan lainnya.

[1] Sintawati, D. A. I., Joebagjo, H., \& Agung, L. S. (2018). Pengaruh Pemanfaatan Aplikasi Penilaian Kinerja Guru Terhadap Peningkatan Profesionalisme Guru. TEKNODIKA Jurnal Penelitian Teknologi Pendidikan, 16(1). DOI: https://doi.org/10.20961/teknodika.v16i1.34754

[2] Mustofa, A. F., \& Majaruni, M. I. (2018). Sistem Pendukung Keputusan Penilaian Kinerja Guru Menggunakan Metode Simple Additive Weighting. Cahaya Tech Journal of Computer, Engineering, and Technology, 7(1). DOI: https://doi.org/10.47047/ct.v7i1.1 .

[3] Triansyah , J., \& Prasetyo, N. A. (2020). Sistem Pendukung Keputusan Penilaian Kinerja Karyawan Terbaik Pada CV. Sumber Karya Teknik Tangerang Menggunakan Metode SAW (Simple Additive Weighting) Berbasis Website. Jurnal Teknik Informatika (JIKA) Universitas Muhammadiyah Tangerang, $\begin{array}{llll}\text { Tangerang, } & 4(1), & 42-48 . & \text { DOI: }\end{array}$ https://doi.org/10.31000/jika.v4i1.2283 .

[4] Haswan, F. (2019). Application of Simple Additive Weighting Method to Determine Outstanding School Principals. Sinkron Jurnal \& Penelitian Teknik Informatika, 3(2). DOI: https://doi.org/10.33395/sinkron.v3i2.10082

[5] Fujita, H, \& Ko, Y. C. (2014). The Conditional Fuzzy Densities of Subjective Decision Support Systems for WCY 2012. Procedia Computer Science, 31. DOI: https://doi.org/10.1016/j.procs.2014.05.333 .

[6] Setiawan, N., Nasution, M. D. T. P., Rossanty, Y., Tambunan, A. R. S., Girsang, M., Agus, R. T. A., Yusuf, M., Vebrianto, R., Purba, O. N., Fauzi, A., Perdana, S., \& Nisa, K. (2018). Simple Additive Weighting as Decision Support System for Determining Employees Salary. International Journal of Engineering \& Technology, 7(2.14), 309-313.

[7] Limbong, T., Sitorus, L., Purba, D., \& Simarmata, J. (2018). Implementation of Simple Additive Weighting Method in Teachers Teaching Assessment Quality. Proceedings of the 1st Unimed International Conference on Economics Education and Social Science, $1, \quad 347-350 . \quad$ DOI: https://doi.org/10.5220/0009492103470350 .

[8] Ayshwarya, A. P. B., Nguyen, P. T., Hashim, W., Rinjani, F., Muslihudin, M., Shankar, K., Denisova, O. P., \& Maseleno, A. (2019). The Best of Village Head Performance: Simple Additive Weighting Method. International Journal of Recent Technology and Engineering (IJRTE), 8(2S3). DOI: https://doi.org/10.35940/ijrte.B1286.0782S319 .

[9] Sokibi, P., \& Setiawan, A. N. (2018). Sistem Pendukung Keputusan Penilaian Kinerja Karyawan PT Harjamukti Jaya Mandiri Menggunakan Metode Simple Additive Weighting. Jurnal Teknik Informatika dan Sistem Informasi, 5(1), 109-118. DOI: https://doi.org/10.35957/jatisi.v5i1.121 .

[10]Wahyudi, Santony, J., \& Nurcahyo, G. W. (2020). Akurasi Keputusan dalam Penentuan Guru Berprestasi dengan Menggunakan Metode Simple Additive Weighting (Studi Kasus Sekolah Menengah Kejuruan Muhammadiyah Batam). Jurnal 
Sistim Informasi dan Teknologi, 2(1), 9-14. DOI: https://doi.org/10.37034/jsisfotek.v2i1.27 .

[11] Sinaga, B. S., \& Riandari, F. (2020). Implementation of Decision Support System for Determination of Employee Contract Extension Method Using SAW. Journal of Computer Networks, Architecture and High Performance Computing, 2(2), 183-186. DOI: https://doi.org/10.47709/cnapc.v2i2.397

[12] Triansyah, J., \& Prasetyo, N. A. (2020). Sistem Pendukung Keputusan Penilaian Kinerja Karyawan Terbaik Pada CV. Sumber Karya Teknik Tangerang Menggunakan Metode SAW (Simple Additive Weighting) Berbasis Website. Jurnal Teknik Informatika (JIKA) Universitas Muhammadiyah Tangerang, 4248. DOI: https://doi.org/10.31000/jika.v4i1.2283 .
[13] Yuhelmi, Musfawati. (2018). Sistem Pendukung Keputusan dengan Metode Simple Additive Weighting (SAW) Untuk Pemilihan Pemimpin Organisasi. Ina-Rxiv Paper. DOI: https://doi.org/10.31227/osf.io/sdu8y .

[14] Ambarwati, T., \& Masya, F. (2020). Application Performance Assessment Work Using Simple Additive Weighting (SAW) Method. Jurnal Riset Informatika, 2(3). DOI: https://doi.org/10.34288/jri.v2i3.146 .

[15] Rismawati, T., Pangestu, M. A., \& Almais, A. T. W. (2020). Penerapan Decision Support System Dynamic Menggunakan Simple Addictive Weighting dalam Penentuan Pegawai Terbaik. Jurnal Ilmiah Informatika, 5(1). DOI: https://doi.org/10.35316/jimi.v5i1.547 